\title{
Design of Circular Slot Antenna for UWB Applications
}

\author{
AMINU Sha'awanatu, Hongxing Zheng * \\ Institute of Antenna and Microwave Techniques \\ Tianjin University of Technology and Education, Tianjin 300222, China \\ *Email: hxzheng@126.com
}

Keywords: UWB Antenna; Bandstop Filter Element; Circular Slot

\begin{abstract}
To reduce the size of wireless equipment, an ultra wide band (UWB) antenna is designed in this paper, and much smaller size is implemented. The antenna has a circular slot on the radiating element for wireless applications. By using microstrip structure, the proposed antenna is designed to work on a thick substrate $\mathrm{h}=1.14 \mathrm{~mm}$ with relative permittivity $\mathrm{\varepsilon r}=3$. Its measured bandwidth covers the UWB band from $2.2 \mathrm{GHz}$ to more than $12 \mathrm{GHz}$, that is, $138 \%$ fractional band width for return loss less than $-10 \mathrm{~dB}$.
\end{abstract}

\section{Introduction}

In the modern era, Ultra Wide Band (UWB) started in the early 1960s, which was operated in the time domain electromagnetic and was led by Harmuth at Catholic University of America, Ross and Robins at Sperry Rand Corporation, and van Etten at the United States Air Force Rome Air Development Center [1], [2]. A major breakthrough in UWB communications occurred as a result of the development of the sampling oscilloscope by both Tektronix and Hewlett-Packard, which provided a method to display and integrate UWB signals, and also provided simple circuits necessary for sub nanosecond baseband pulse generation [3], [4]. At that time, this technology was alternately referred to as baseband, carrier-free or impulse. The term Ultra Wideband was not applied to this technology until approximately 1989; and by this time, the Department of Defense created the nomenclature Ultra Wide Band, in order to describe communication through the transmission and reception of impulses. In 1993, Robert Scholtz at the University of Southern California wrote a landmark paper that presented a multiple access technique for UWB communication systems [5]. Scoltz's technique allocated each user a unique spreading code that determined specific instances in time when the user is allowed to transmit. With viable multiple access scheme, UWB became capable of supporting not only radar and point-to-point communications but wireless networks as well. In 1994, McEwan developed the Micro power impulse Radar, which provided a compact, inexpensive, low power UWB system for the first time [6]. It allowed the frequency band between 3.1 and $10.6 \mathrm{GHz}$ for unlicensed Ultra-wideband transmission. This very low emitted power means that UWB devices are more adapted or have short range communications, up to few tens of meters. Their battery life is no longer limited by the necessary output power at the antenna, but by the back-end power consumption and pulse detection techniques [7].

The UWB bandwidth is the frequency band bounded by the points measured at $-10 \mathrm{~dB}$ below the peak emission point, based on the complete transmission system including the antenna. Thus the center frequency of the UWB bandwidth is designated as:

$$
f_{c}=\frac{f_{h}+f_{l}}{2}
$$

Where, fh is upper operational frequency, $\mathrm{fl}$ is lower operational frequency, and $\mathrm{fc}$ is the center frequency of the UWB bandwidth. The fractional BW is defined as 


$$
F B W=2 \frac{f_{h}-f_{l}}{f_{h}+f_{l}} * 100 \%=\frac{f_{h}+f_{l}}{f_{c}} * 100 \%
$$

UWB has a number of encouraging advantages, which are the reasons why it presents a more eloquent solution to wireless broadband than other technologies. However, UWB has to share the spectrum with several other radio communication systems in the market. The UWB transmitted power is much lower than the other systems, which make it appear as noise to the narrowband applications and the transmission power is high. The systems must produce broad operating bandwidths for impedance matching, high gain transmissions in the desired direction, stable transmission patterns and gains, consistent group delays, high transmission efficiency, and low profiles. Various studies have been devoted to evaluate the performance of UWB antennas [8]-[12]. The main challenge to design UWB antenna comes from the coverage of large bandwidth, because the matching and energy transmission require to be verified for the entire bandwidth. A suitable UWB antenna should provide an absolute bandwidth no less than $500 \mathrm{MHz}$ or a fractional bandwidth at least 0.2 . This is the minimum bandwidth, but generally UWB antenna should operate over the entire $3.1 \mathrm{GHz}-10.6 \mathrm{GHz}$ frequency range, resulting in spanning $7.5 \mathrm{GHz}$.

This paper presents the design of UWB antenna, which is different from other antenna in terms of its ultra wide frequency bandwidth. The design of UWB antenna with circular slot, bandstop filter element, or radiating element was analyzed by using HFSS software package [13]. In summary, physically small size, wide bandwidth and high efficiency are the desired characteristics of antennas in mobile systems.

\section{Geometry Design}

After a comprehensive investigation of new wide bandwidth, low-profile and compact antenna, this paper mainly focuses on analyzing how the antenna operate within the UWB range [14], and it was found to be a good candidate for use in UWB wireless technology. The structure of this UWB antenna is similar to the most useful antennas at microwave frequencies ( $\mathrm{f}>1 \mathrm{GHz}$ ), it consists of a radiating metallic patch (normally made up with conducting material such as tin, gold, or nickel) or an array of patches situated on top of the grounded dielectric substrate, and this antenna is known as patch antenna/or microstrip patch antenna. In summary, the proposed antenna consists of three layers: the top is a radiator/radiating element, and the middle is a substrate with dielectric constant. The substrate is to provide mechanical supports for the radiating patch elements and to maintain the required precision spacing between the patch and its ground plane. The bottom is an etched partial ground plane that can increase the bandwidth of the antenna. This UWB antenna is supported by a dielectric substrate of height $\mathrm{h}$ of $1.14 \mathrm{~mm}$ and relative permittivity $\varepsilon r=3$. The patch of this proposed antenna is circular with radius $\mathrm{R}=5 \mathrm{~mm}$, the ground plane is $\mathrm{L} 2 \times \mathrm{W} 1(15 \times 30 \mathrm{~m} 2)$, Microstrip feed line L3 is $15.5 \mathrm{~mm}$, the Width of the Microstrip feed line W2 is $2 \mathrm{~mm}$ for a characteristic impedance of $50 \mathrm{ohms}$, and the radius of circular slot $r$ is $2 \mathrm{~mm}$. This antenna is optimized to cover UWB bandwidth and to miniaturize the antenna size. This type of antenna can easily be integrated into system circuits for a compact design and fabricated at a very low manufacturing cost. The geometry of this type of antenna is depicted in Fig. 1.

The S11 (dB), known as return loss or reflection coefficient, is the most commonly quoted parameter in regards to antennas. It represents how much power is reflected to the antenna. If $\mathrm{S} 11=$ $0 \mathrm{~dB}$, no reflection on the transmission line $(\mathrm{ZL}=\mathrm{Zo})$ is called match condition, and then $100 \%$ of the power is transferred to the antenna. If $S 11=-10 \mathrm{~dB}$, it implies that if $3 \mathrm{~dB}$ of the power is delivered to the antenna, $-7 \mathrm{~dB}$ is the reflected power. The reminder of the power is delivered to the antenna, which is either radiated or absorbed as losses within the antenna. Since antennas are typically designed to be low loss, ideally the majority of the power delivered to the antenna is radiated. Mathematically return loss or reflection coefficient is defined as

$$
\Gamma=\frac{Z_{L}-Z_{O}}{Z_{L}+Z_{O}}
$$


Where, ZL is Load Impedance, $\mathrm{ZO}$ is Characteristics impedance of the antenna, and $\Gamma$ is Reflection coefficient / return loss $(\mathrm{dB})$. For the function of reflection coefficient describing the power reflected from the antenna and being known as VSWR (Voltage Standing Wave Ratio), it is denoted by $\rho$ and is given by

$$
\rho=\frac{1+|\Gamma|}{1-|\Gamma|}
$$

If $\rho$ is below 2 , the antenna match is considered very well, and little would be gained by impedance matching (the process of reducing the power reflected from the antenna and maximizing the power delivered to the antenna). As $\rho$ increases, there are two main negatives: (i) more power is reflected from the antenna and thus not transmitted. (ii) More power is reflected to the radio transmitting large amount of reflected power, which can damage the radio.

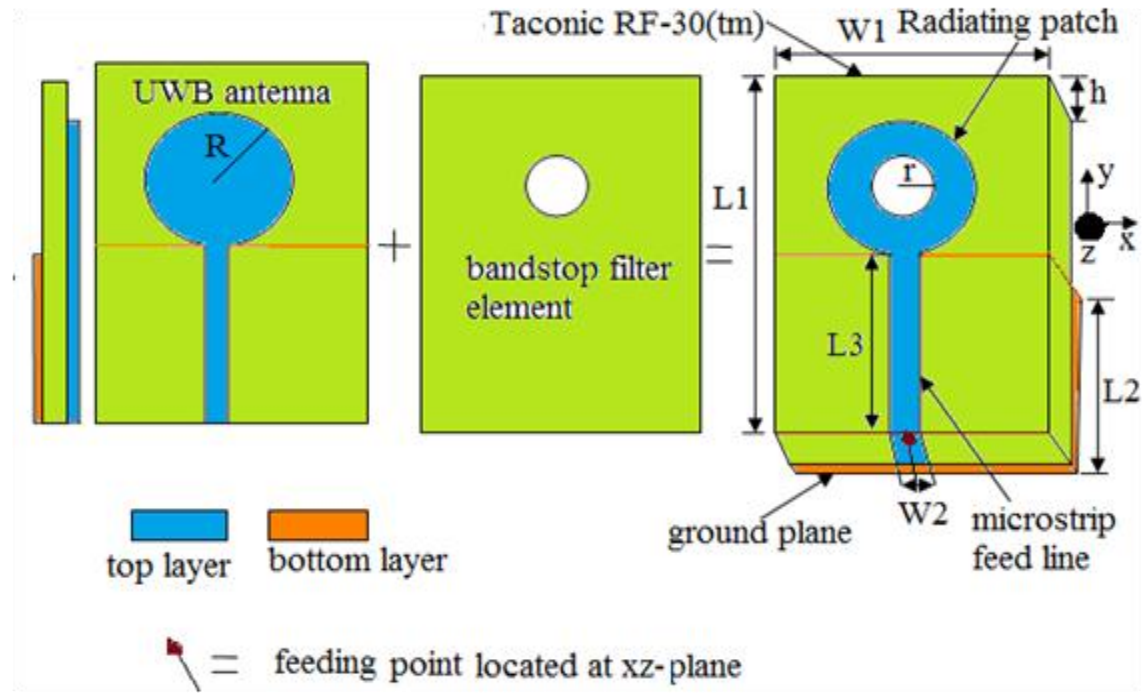

Fig. 1 Geometry of Circular Slot Monopole Antenna

Therefore, researchers obtained the parameters of this antenna; it has been given in Table 1. By using high frequency structure simulator (HFSS) software, researchers investigate the $-10 \mathrm{~dB}$ bandwidths of the Circular slot antenna for different radius $\mathrm{R}$, results are given in the Table 2 .

Table 1 Parameters of the Proposed Antenna

\begin{tabular}{lccccccc}
\hline Dimensions & L1 & W1 & L2 & R & r & W2 & L3 \\
Length(mm) & 30 & 30 & 15 & 5 & 2 & 2 & 15.5 \\
\hline
\end{tabular}

Table 2 Simulated -10dB Bandwidths of the Circular Slot Antenna for Different Radius R

\begin{tabular}{ccccc}
\hline $\mathbf{R}(\mathrm{mm})$ & $\mathbf{f}_{\mathbf{L}}(\mathbf{G H z})$ & $\mathbf{f}_{\mathbf{U}}(\mathbf{G H z})$ & AbsoluteBW(GHz) & FractionalBW(\%) \\
\hline 5.5 & 2.29 & 9.87 & 7.58 & 125 \\
5.6 & 2.09 & 12.00 & 9.91 & 141 \\
5.7 & 2.18 & 12.00 & 9.82 & 139 \\
\hline
\end{tabular}

\section{Simulation Result}

The radiation pattern in the azimuthal plane of the antenna was obtained at 3 frequencies, $4.5 \mathrm{GHz}$, $6 \mathrm{GHz}$ and $7.2 \mathrm{GHz}$ inside the UWB band. It is found that the H-plane radiation pattern at yz - plane 
throughout the band of frequencies are purely omni-directional pattern, and E-plane radiation pattern at $\mathrm{xz}$ - plane in the form of eight shapes is shown in Fig. 2.

\section{Conclusion}

UWB antenna with partial ground plane was designed to increase the bandwidth of the antenna; such large bandwidth offers advantages of signal robustness, information content and/ or implementation simplicity. Moreover, interference is a serious problem for UWB application systems, so band stop filter is used to reduce the interference between the UWB systems and the existing wireless systems. In this paper, band stop filter is obtained by embeddings a circular slot in the radiating patch, in order to reduce the interference. The proposed antenna is critically dependent on the radius $\mathrm{R}$ of the circular patch, and the impedance bandwidth between $2.1 \mathrm{GHz}$ to more than $12 \mathrm{GHz}$ is suitable for Voltage Standing Wave Ratio, VSWR below 2. The frequency bands cover the standard IEEE $802.11 \mathrm{~b} / \mathrm{g}(2.4-2.285 \mathrm{GHz})$ and IEEE $802.11 \mathrm{a}(5.15-5.35 \mathrm{GHz}, 5.725-$ $5.875 \mathrm{GHz})$ for Wireless Local Area Network, WLAN applications and $2.5 \mathrm{GHz}(2.5-2.69 \mathrm{GHz})$, $3.5 \mathrm{GHz}(3.3-3.8 \mathrm{GHz})$ and $5 \mathrm{GHz}(5.25-5.85 \mathrm{GHz})$ for WiMAX applications. Circular slot is etched on the radiator of the proposed antenna to control impedance matching. This type of antenna can easily be integrated into system circuits for a compact design and fabricated at a very low manufacturing cost.

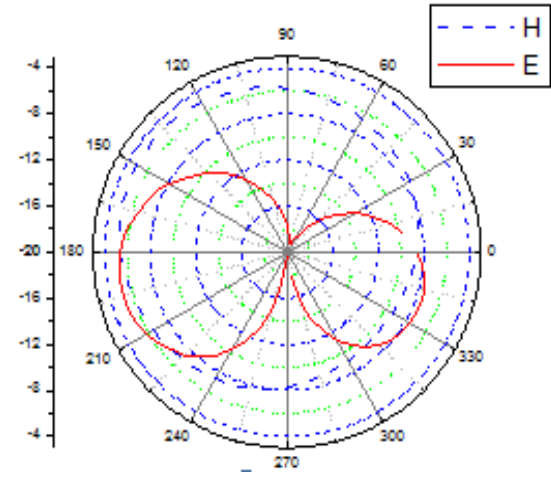

(a)

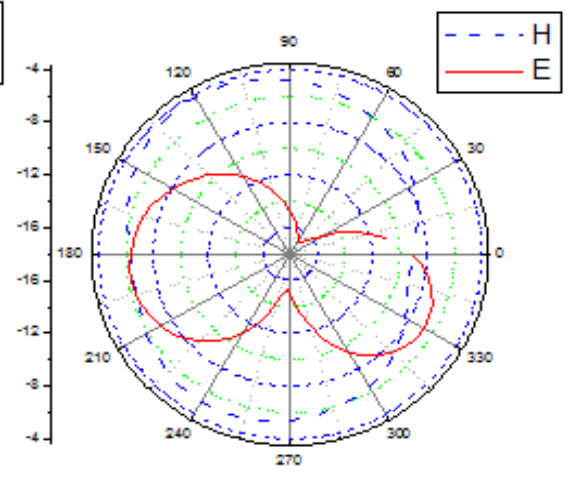

(b)

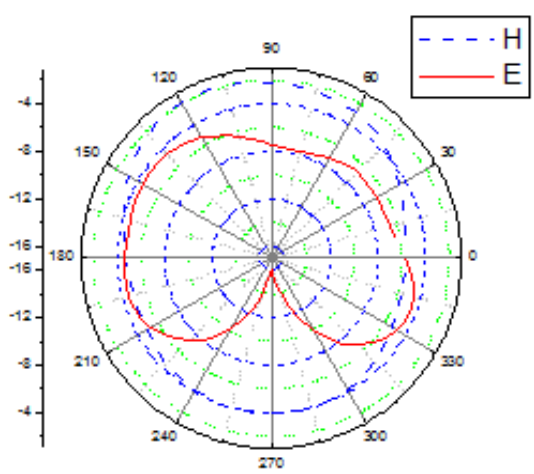

(c)

Fig. 2 Radiation Pattern at (a) $4.5 \mathrm{GHz}$, (b) $6 \mathrm{GHz}$, and (c) $7.2 \mathrm{GHz}$

\section{Acknowledgments}

This work was supported by the National Nature Science Foundation of China, the Natural Science Foundation of Tianjin Municipality and Advanced Technology, China, and the Science Research and Development Foundation of Tianjin University of Technology and Education, China, Grant 61371043, 12JCYBJC10500, and KJY14-04, respectively.

\section{References}

[1] K. Thirumalaivasan and R. Nakkeeran, Revision of Part 15 of the Commission's Rules Regarding Ultra-wideband Transmission Systems, First Note and Order, Federal Communications Commission, ET-Docket 98-153, released April 22, 2002.

[2] T. W. Barrett, History of Ultra Wideband (UWB) Radar and Communications: Pioneers and Innovators, Proc. Progress in Electromagnetics Symposium (PIERS) 2000, Cambridge, MA, July 2000 .

[3] T. W. Barrett, History of Ultra-wideband Communications and Radar: Part 1, UWB Communications, Microwave Journal, 60(2001) 22-56. 
[4] R. J. Fontana, A Brief History of UWB Communications". Available: http://www. multispectral. Com / history. html

[5] R. A. Scholtz, Multiple Access with Time-hopping Impulse Modulation, IEEE MILCOM, 2(1993), 447-450.

[6] T. E. McEwan, Ultra-wideband Radar Motion Sensor, U.S. Patent 5,361,070. (1994)

[7] D. Barras F. Ellinger, H. Jackel, A Comparison between Ultra-wideband and Narrowband Transceivers, Proc. International Conference on Wireless Communications, Calgary, Canada, July 2002.

[8] K. Thirumalaivasan and R. Nakkeeran, New Public Safety Applications and Broadband Internet Access among Uses Envisioned by FCC Authorization of Ultra-wideband Technology, First Report and Order (FCC 02-48). Action by the Commission February 2002.

[9] L. T. Chang and W. D. Burnside, An Ultra Wide-bandwidth Tapered Resistive TEM Horn Antenna, IEEE Transactions on Antennas and Propagation, 48(2000) 1848-1857.

[10] R. Garg, P. Bhartia, I. Bahl, and A. Ittipiboon, Microstrip Antenna Design Handbook, Artech House, Norwood, MA, 2001.

[11] N. P. Agrawall, G. Kumar, K. P. Ray, Wide-band Planar Monopole Antenna. IEEE Trans. Antennas Propag, 48(1998) 294-295.

[12] M. J. Ammann, Z. N. Chen, Wideband Monopole Antennas for Multi-Band Wireless Systems, IEEE Antennas and Propagation Magazine, (2003).

[13] T. W. Hertel, G. S. Smith, On the Dispersive Properties of the Conical Spiral Antenna and Its Use for Pulsed Radiation, IEEE Trans. Antennas Propag., 51 (2003) 66-78.

[14] Klemm, M. I. Z. Kovics, G. F. Pedersen, and G. Troster, Novel Small Size Directional Antenna for UWB/ WBAN/WPAN Applications. IEEE Trans. Antennas Propag, 12(2005) 3884-3896. 